\title{
Ants Correctly Locate the Zero in a Continuous Series of Numbers
}

\author{
Marie-Claire Cammaerts ${ }^{1} \&$ Roger Cammaerts ${ }^{2}$ \\ ${ }^{1}$ Biology of Organisms Department, University of Brussels, Belgium \\ ${ }^{2}$ Natural and Agricultural Environmental Studies Department (DEMNA) of the Walloon Region, Belgium \\ Correspondence: Marie-Claire Cammaerts, Independent Researcher, 27, Square du Castel Fleuri, 1170 Bruxelles, \\ Belgium. Tel: 32-2-673-4969. E-mail: mtricot@ulb.ac.be; mccammaerts@gmail.com
}

Received: June 14, 2019

doi:10.5539/ijb.v11n4p16
Accepted: July 2, 2019

Online Published: July 11, 2019

URL: https://doi.org/10.5539/ijb.v11n4p16

\begin{abstract}
Knowing that the workers of the ant Myrmica sabuleti have a concrete notion of zero, and that they can expect the time and the place of the next delivery of food, we experimentally examined if these ants could locate the zero at its due cardinal place. The ants were visually trained step by step to a continuous decreasing series of two amounts of elements differing by one unit, and of which, at each step, either the lower or the higher amount was associated with food. The ants were tested at each step of the decreasing series, and each time essentially reacted to the amount of elements which would be associated with the following food delivery. This showed that the ants could distinguish amounts of elements as being lesser or higher by one element, up to and including the absence of element (the zero). At the end of the series, the ants perceived the zero as being ' 1 element less 1' as well as 1 element as being ' 0 element plus 1 '. They thus correctly located the zero at its due cardinal place.
\end{abstract}

Keywords: Conditioning, Expectation, Myrmica sabuleti, Numerosity, Subitizing

\section{Introduction}

Ants can distinguish different numbers of elements, can add numbers when seeing them side by side simultaneously (but not when seeing them consecutively), and have a concrete, basic visual or olfactory notion of zero (i.e. of nothing) (Cammaerts, 2008; M. C. Cammaerts \& R. Cammaerts, 2019c, d; M. C. Cammaerts \& R. Cammaerts, 2019a, b). It remains to know if ants can locate the zero at its numerical proper place which is at the end of a continuous decreasing series of numbers, i.e. following the number 1 , as well as at the start of a continuous increasing series of numbers, i.e. preceding the number 1 . Ants can expect the place as well as the time at which food will be available (M. C. Cammaerts \& R. Cammaerts, 2016a, b). Consequently, it can be presumed that they could also expect the next numbers of elements which should appear when they are confronted to a decreasing or an increasing series of numbers. Should it be the case, then, it will be possible to test if they can correctly expect the zero at the end of a decreasing series of numbers, as well at the start of an increasing series of numbers. Performing such tests is the aim of the present study. Before relating it, we report what is nowadays known on the subject in other animal species.

Many works have been done on the notion of numbers in animals and on their ability in adding numbers, but very few deal with the notion of zero, and rare are those examining if animals set the zero in due place. Works on spiders, fishes, frogs, rats and chicks for instance revealed their ability in distinguishing numbers and even adding and subtracting, but did not consider if they have some notion of zero (respectively: Rodriguez, Briceno, Briceno-Aguilar, \& Höbel, 2015; Agrillo, Dadda, Serena, \& Bisazza, 2008; Rose, 2018; Cox \& Montrose, 2016; Rugani, Vallortigara, Priftis, \& Regolin, 2015). More information, with more examples, is given in Pearce (2008). Also, most of the works made on birds' and monkeys' numerosity abilities deal with the notion of numbers and of adding without examining that of zero (e.g. Xia, Sieman, \& Delius, 2000; Brannon, Herbert, \& Terrace, 1998; Hauser, Carey, \& Hauser, 2000). The notion of zero has been considered by a few researchers working on birds, monkeys and human children, however without clearly elucidating if these individuals correctly locate the zero in a continuous series of numbers, though it can often be presumed that they can do so (e.g. Pepperberg \& Gordon, 2005; Merritt, Rugani, \& Brannon, 2009; Biro \& Matsuzawa, 2001; Merritt \& Brannon, 2013). Coming back to insects, and to hymenoptera, an important work has been made on bees. These insects have the notion of zero and might be able to locate it correctly in a series of elements: they can recognize zero element when progressively trained to choose a set with less elements than the previous set, and have thus been shown to correctly locate the 
zero comparatively to 1-5 elements (Howard, Avarguès-Weber, Garcia, Greentree, \& Dyer, 2018). Investigating on this subject in ants should enlarge our knowledge on the insects' notion of numbers and zero, and at the same time fill the gap still remaining in our study on the ants' numerosity concept.

\section{Material and Methods}

\subsection{Collection and Maintenance of Ants}

The experiments were performed on six colonies of M. sabuleti (labeled A to F) collected in June 2018 in an abandoned quarry at Marchin (Condroz, Belgium), and in September 2018, in an abandoned quarry of the Aise valley (Ardenne, Belgium). Each colony contained about 500 workers, brood and a queen. They have been maintained in the laboratory in two to four glass tubes half filled with water, a cotton plug separating the ants from the water. For each colony, these tubes were set in a tray $(34 \mathrm{~cm} \times 23 \mathrm{~cm} \times 4 \mathrm{~cm})$ which served as foraging area. In this area, pieces of Tenebrio molitor larvae (Linnaeus, 1758) were provided three times per week and cotton plugged tubes filled with sugar water were permanently set. The ambient temperature was $c a 20^{\circ} \mathrm{C}$, the humidity $80 \%$, the lighting 330 lux while working on ants, and the electromagnetism $2 \mu \mathrm{Wm}^{2}$. All these environmental conditions were optimum for the species.

2.2 Cues Presented to the Ants

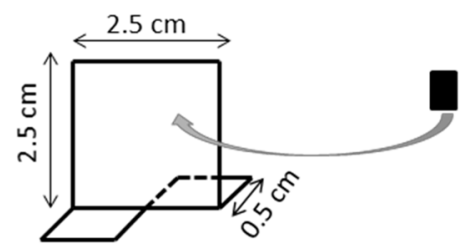

Cues (stands + numbers of elements) used:

5

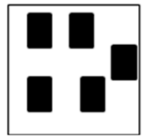

Experiment I

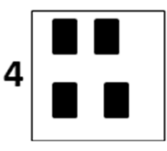

3

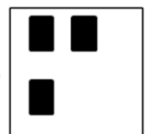

, B, C

\begin{tabular}{|c|c|c|c|c|c|}
\hline \multicolumn{3}{|c|}{ Training } & \multicolumn{3}{|c|}{ Testing } \\
\hline 2 days & 5 & $4+$ reward & I & 5 & 4 \\
\hline 2 days & 4 & $3+$ reward & I & 4 & 3 \\
\hline 2 days & 3 & $2+$ reward & I & 3 & 2 \\
\hline 1 day & & & & 2 & 1 \\
\hline 2 days & 2 & $1+$ reward & I & 2 & 1 \\
\hline 1 day & & & & 1 & 0 \\
\hline
\end{tabular}
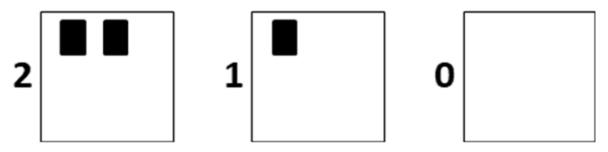

Experiment I I on colonies D, E, F

\begin{tabular}{llllll} 
& \multicolumn{2}{l}{ Training } & \multicolumn{3}{c}{ Testing } \\
2 days & 4 & $5+$ reward & $/$ & 4 & 5 \\
2 days & 3 & $4+$ reward & $/$ & 3 & 4 \\
2 days & 2 & $3+$ reward & $/$ & 2 & 3 \\
1 day & & & & 1 & 2 \\
2 days & 1 & $2+$ reward & $/$ & 1 & 2 \\
1 day & & & & 0 & 1
\end{tabular}

Q: $O$ at the start of an increasing series?

Figure 1. Cues (numbers of elements) used and experimental planning conducted

The aim was to examine if ants could set the zero at its proper place at the end of a decreasing series of numbers (i.e. considering the 0 as being less than the number 1 , when rewarded to $4,3,2,1$ vs $5,4,3,2$ ) and at the beginning of an increasing series of elements (i.e. considering 1 element as being higher than 0 element, when rewarded to $5,4,3,2$ vs $4,3,2,1)$.

The elements presented to the ants were rectangles $(0.4 \mathrm{~cm} \times 0.6 \mathrm{~cm})$ drawn using software Power Point ${ }^{\circledR}$, printed on white paper, then tied to stands $(2.5 \mathrm{~cm} \times 2.5 \mathrm{~cm})$ made of strong white paper (Steinbach $\AA$ ) and maintained vertically thanks to their duly folded horizontal base $(2 \times[1.25 \mathrm{~cm} \times 0.5 \mathrm{~cm}])$ (Figure 1, upper part). The number of elements tied to a stand differed according to the step of the conducted experiment (I and II; Figure 1, lower 
part), what is detailed below (see 2.4. Experimental Protocol). During the training part of each experimental step, two stands bearing elements were presented to the ants: one of them was set aside the ants' food; the other one was set far from the food (Figure 2). The two stands were at about $12 \mathrm{~cm}$ of distance from one another, and the angle made by their front parts, i.e. those bearing the elements, equaled about $90^{\circ}$. During the testing part of each experimental step, two new (never used) stands similar to those used for training were presented to the ants in a separate tray (see below: 2.3. Experimental Design and Figure 2).

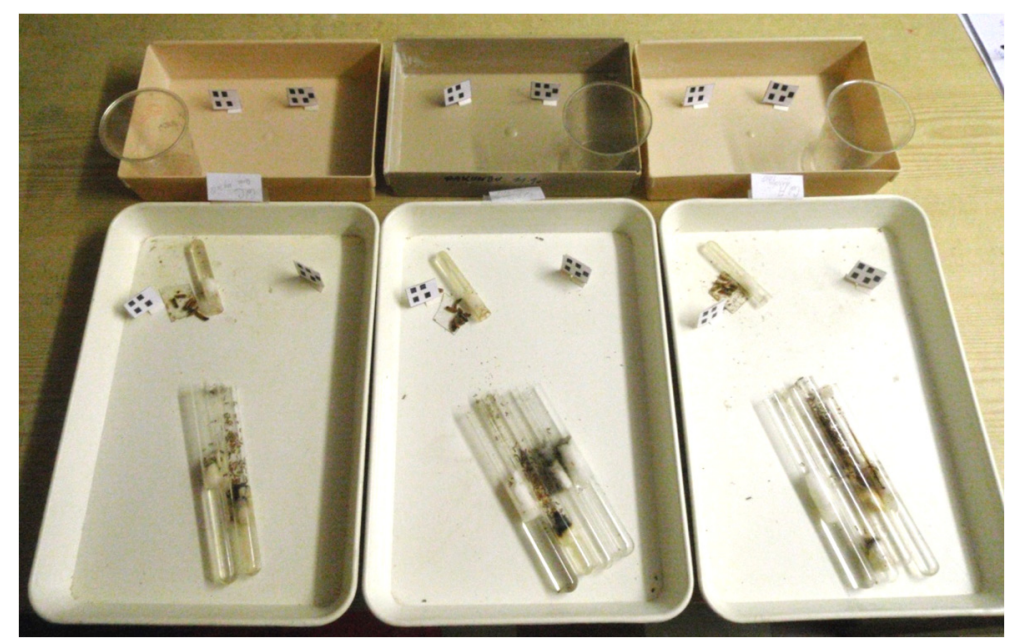

Figure 2. Experimental design

This experimental design was used to condition the ants (on their tray, lower part of the photo) to a number of elements versus another number, using successively lower or higher numbers of elements, and to test each time the ants (in a separate tray, upper part of the photo) for examining if the ants could locate the 'zero' at its due place, i.e. at the end of a decreasing series of numbers (below the number 1) as well as at the beginning of an increasing series of numbers (the number 1 being above the zero).

\subsection{Experimental Design}

Such a design is shown is Figure 2. The ants' training occurred on their foraging area: a stand with a given number of elements was set aside their food; another stand with another number of elements was set far from that food. During the training, the ants saw the two presented stands either simultaneously or consecutively, as well as either on their left, or in front of them, or on their right, all this in any order.

The ants' testing occurred in a separate tray $(30 \mathrm{~cm} \mathrm{x} 15 \mathrm{~cm} \mathrm{x} 4 \mathrm{~cm})$, one for each used colony, the borders of which having been slightly covered with talc to prevent escaping. In these trays, two stands bearing the same numbers of elements as those used to train the ants were set at about $10-12 \mathrm{~cm}$ from one another. The stand bearing the same number of elements as that set near the food during training was located on the left in the tray devoted to test during about half of the tests, and was located on the right during the other tests.

\subsection{Experimental Protocol}

Experiment I was made on colonies A, B and C; experiment II was made on colonies D, E and F. Each experiment included six steps summarized in Figure 1, lower part.

For experiment I, the six steps were the following ones. During two days, the ants were trained to 4 elements set near the food and 5 elements set far from the food; the ants were then tested in front of these two numbers of elements. During the two following days, the ants were trained to 3 elements set near the food and 4 elements set far from the food; the ants were then tested in front of these two numbers of elements. During the next two following days, the ants were trained to 2 elements set near the food and to 3 elements set far from the food; they were then tested in front of these two numbers of elements. After that, no food was given to the ants and, 24 hours later, they were tested in front of 1 and 2 elements. They were then fed again and trained during two days to 1 element set near their food and 2 elements set far from the food; they were then again tested in front of 1 and 2 elements. After that, no food was given to the ants and, 24 hours later, they were tested in front of 0 and 1 element. The experiment I then ended. It used a decreasing series of elements finishing by zero. 
For experiment II, the six steps were the following ones. During two days, the ants were training to 5 elements set near the food and 4 elements set far from the food; the ants were then tested in front of these two numbers of elements. During the two following days, the ants were trained to 4 elements set near the food and 3 elements set far from the food; the ants were then tested in front of these two numbers of elements. During the next two following days, the ants were trained to 3 elements set near the food and 2 elements set far from the food; they were then tested in front of these two numbers of elements. After that, no food was given to the ants and, 24 hours later, they were tested in front of 2 and 1 elements. They were then fed again and trained during two days to 2 elements set near their food and 1 element set far from the food; they were then again tested in front of 1 and 2 elements. After that, no food was given to the ants and, 24 hours later, they were tested in front of 1 and 0 element. The experiment II then ended. It used, in an inverse order, an increasing series of elements starting by zero.

At each training day, the ants of each three colonies being in the vicinity of the two presented stands were counted six times over each day, and the three mean values were established (Tables 1 and 2, upper part).

For making a test, 25 ants of each three colonies were transferred into their tray devoted to testing (Figures 2, 3 and 4), and the ants present at a distance of $0-2 \mathrm{~cm}$ from each of the two presented stands were counted 20 times over 10 experimental minutes. The means of these counts were established (Tables 1and 2, lower part) and the proportion of correct responses (= the proportion of ants choosing the number of elements set near the food during training) was calculated for each experimental step (these proportions are only given in the text, not in a table).

\subsection{Statistical Analysis}

The numbers recorded during training did not require statistical analysis.

Those recorded during each testing step were statistically analyzed as follows. For each two presented numbers of elements, the 20 numbers of ants of the three used colonies were chronologically arranged and added by four over the experimental time, and the five sums (not written in the tables but given in the text) obtained for each two presented numbers of elements were compared to one another using the non parametric test of Wilcoxon (Siegel \& Castellan, 1989).

\section{Results}

\subsection{Experiment $I$}

The numerical results of this experiment are given in Table 1, those relative to training are in the upper part of the table, and those relative to testing are in its lower part. Each step is illustrated by a photo given in Figure 3 .

Table 1. Results of experiment I made to examine if ants could place the zero at the end of a decreasing series of numbers, i.e. after the number 1

\begin{tabular}{|c|c|c|c|c|c|c|c|c|c|c|c|c|c|c|c|c|c|}
\hline \multirow{2}{*}{$\begin{array}{l}\text { Training } \\
\text { Presented nos }\end{array}$} & \multicolumn{17}{|c|}{ Mean numbers of ants around the presented numbers of elements } \\
\hline & \multicolumn{5}{|c|}{5 and $4+$ reward } & \multicolumn{4}{|c|}{4 and $3+$ reward } & \multicolumn{4}{|c|}{3 and $2+$ reward } & \multicolumn{4}{|c|}{2 and $1+$ reward } \\
\hline Colony A & \multicolumn{5}{|c|}{8.0} & \multicolumn{4}{|c|}{9.6} & \multicolumn{4}{|c|}{5.9} & \multicolumn{4}{|c|}{8.8} \\
\hline Colony B & \multicolumn{5}{|c|}{6.3} & \multicolumn{4}{|c|}{8.0} & \multicolumn{4}{|c|}{10.5} & \multicolumn{4}{|c|}{11.3} \\
\hline Colony $\mathrm{C}$ & \multicolumn{5}{|c|}{7.2} & & 9.1 & & & \multicolumn{4}{|c|}{10.8} & \multicolumn{4}{|c|}{9.9} \\
\hline Testing & \multicolumn{17}{|c|}{ Mean numbers of ants responding to the presented numbers of elements } \\
\hline Presented $\mathbf{n}^{\text {s }}$ & \multicolumn{3}{|c|}{5 and 4} & \multicolumn{3}{|c|}{4 and 3} & \multicolumn{3}{|c|}{3 and 2} & \multicolumn{3}{|c|}{2 and 1} & \multicolumn{2}{|c|}{2 and 1} & \multicolumn{3}{|c|}{1 and 0} \\
\hline Colony A & 0.9 & and & 3.6 & 0.6 & and & 2.3 & 1.3 & and & 3.8 & 0.4 & and & 2.9 & 1.2 and & 5.7 & 0.9 & and & 3.0 \\
\hline Colony B & 0.5 & and & 2.9 & 0.5 & and & 2.9 & 0.9 & and & 5.2 & 0.6 & and & 3.3 & 0.6 and & 3.4 & 0.8 & and & 3.1 \\
\hline Colony C & 0.7 & and & 2.8 & 0.7 & and & 3.2 & 0.6 & and & 3.2 & 0.6 & and & 2.0 & 0.6 and & 2.9 & 0.9 & and & 3.2 \\
\hline
\end{tabular}

The elements, their numbers, the experimental planning and design are shown in Figures 1 and 2. Means, proportions and statistics are given in the text. The results of the testing sessions made without previously training the ants are written in bold. The first results showed that the ants could expect that the following number of elements present near their food will be 1 element (i.e. the previous correct number less 1). The second results showed that the ants could expect that the following number of element present near their food will be 0 element, and revealed at the same time that the ants located the zero (0) at the end of a continuous decreasing series of elements, i.e. perceiving 0 as being less than 1 element. 

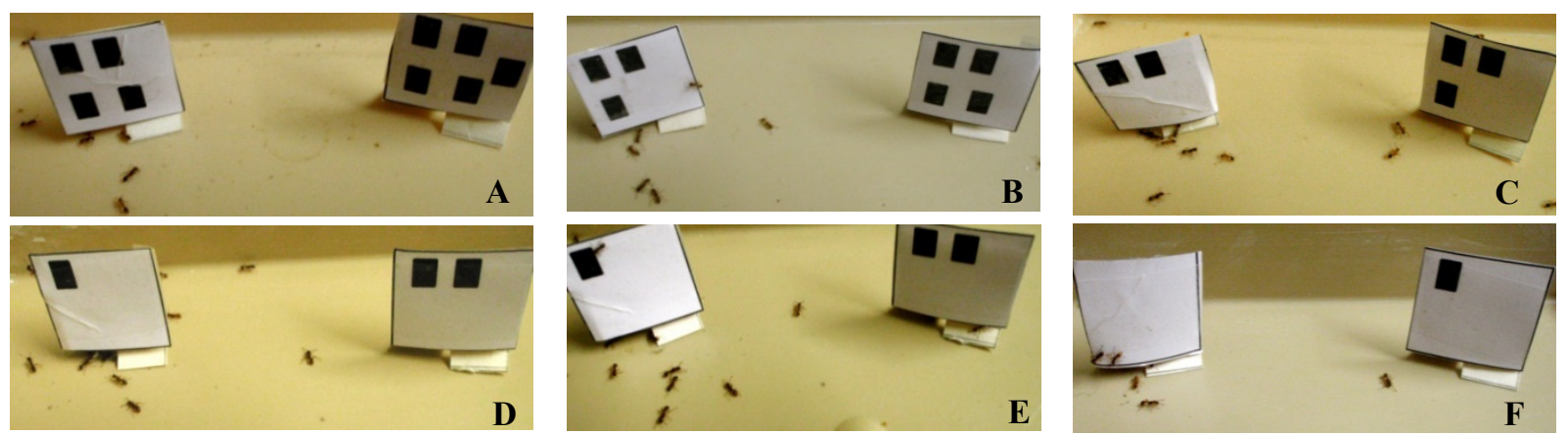

Figure 3. Some views of experiment I

During this experiment, the ants were successively learned to choose 4 vs 5 elements (A), 3 vs 4 elements (B), $2 v s$ 3 elements (C), then presented with 1 and 2 elements (D), then learned to choose 1 vs 2 elements (E), and finally presented with 0 and 1 element (F). The photos $\mathbf{D}$ and $\mathbf{F}$ are those of tests made on ants not trained. They revealed that: (D) ants could expect the following number (1) of elements in a decreasing series of numbers (5 to 1$)$ present near the food, (F) ants could expect the following number (0) of elements in a decreasing series present near the food, and perceived the zero as being at the very end of a decreasing series of numbers.

During the presentation of 5 elements and 4 ones, the latter cue being aside the reward, meanly 7.2 ants were seen visiting these two sites. When tested in front of these two numbers of elements, the ants mostly reacted to 4 elements (186 ants, i.e. $82.3 \%$ having been counted near such a number) and very few to 5 elements ( 40 ants, i.e. $17.7 \%$, were counted in front of that number). Summed by four over the experimental time, the numbers of ants of the three colonies equaled 38,35,30, 44 and 39 for 4 elements, and 6, 6, 6, 11 and 11 for 5 elements, these two series statistically differing $(\mathrm{N}=5, \mathrm{~T}=15, \mathrm{P}=0.031)$.

While 4 elements and 3 ones were presented to the ants, the latter number being near the food, meanly 8.9 ants were seen in the vicinity of these numbers. After having found their food aside 3 elements, and seen 4 elements far of their food, the tested ants of the three colonies reacted essentially to 3 elements. The total number of ants counted in front of 3 elements equaled 167 , i.e. $83.1 \%$, and in front of 4 elements, 34 , i.e. $16.9 \%$. Summed by four over the experimental time, the ants of the two colonies counted near 3 elements were $28,32,38,35$, 34, while those near 4 elements were 1, 7, 11, 8, 7. These two series statistically differed $(\mathrm{N}=5, \mathrm{~T}=15, \mathrm{P}=0.031)$.

During their training to 2 elements set near their food and 3 elements set far from their food, meanly 9.1 ants were seen in the vicinity of these two cues. After having been trained during two days, the tested ants of the three colonies reacted more to 2 elements than to 3 elements. The total number of ants seen near 2 elements equaled 241, i.e. $82 \%$, while that of ants seen near 3 elements equaled 53 , i.e. $18 \%$. Summed by four over the experimental time, the numbers of ants of the three colonies seen near 2 elements equaled 43, 43, 53,51,51, and of those seen near 3 elements equaled $6,12,15,10,9$. These two series of numbers statistically differed $(\mathrm{N}=5, \mathrm{~T}=15, \mathrm{P}=0.031)$.

Without having been trained to 1 element and 2 elements, and having been deprived of food during one day, the tested ants of the three colonies however went essentially towards the stand bearing 1 element. The total number of ants, belonging to the three colonies, seen near 1 element equaled 163 , i.e. $84 \%$, and of ants seen near two elements equaled 31, i.e. $16 \%$. Summed by four over the experimental time, these numbers of counted ants were 34, 27, 32, 35,35 for 1 element, and 4, 5, 3, 10, 9 for two elements. These two series of numbers statistically differed $(\mathrm{N}=5$, $\mathrm{T}=15, \mathrm{P}=0.031$ ). The ants could thus expect that the next number of elements which would be aside their food will be 1 element. The present experiment was, for the ants, an experiment of extinction. Thus, the ants were then fed and trained to 1 (near the food) vs 2 elements (far from the food) during two days.

While being trained to 1 vs 2 elements, meanly 10.0 ants were seen all around the two presented stands, the more numerous being those of colony $\mathrm{B}$, the less numerous ones being those of colony A. After two days of training, the tested ants reacted essentially to 1 element. In total, 238 ants, i.e. $83.5 \%$, were seen near the stand bearing 1 element and 47 ants, i.e. 16.5\%, were seen near the stand bearing 2 elements. Summed by four over the experimental time, the numbers of ants of the three colonies counted in front of 1 element equaled 49, 49, 44, 46, 50 , and those of ants seen in front of 2 elements equaled $9,9,8,14,7$. These two series of numbers statistically differed $(\mathrm{N}=5, \mathrm{~T}=15, \mathrm{P}=0.031)$, the ants having thus correctly responded to 1 element.

The ants were then again deprived of their food for one day, and thereafter tested in front of 0 element and 1 element. When being so tested, without having been trained to these two numbers of elements, the ants of the three 
colonies similarly preferentially responded to 0 element, being in total 184 , i.e. $78.6 \%$, in doing so, while 50 ants, i.e. $21.4 \%$, responded to 1 element. Summed by four over the experimental time, the numbers of ants of the three colonies counted near 0 element equaled 31,37, 44,39,33, and of ants counted near 1 element equaled 9, 11, 9, 12, 9. These two series of numbers statistically differed $(\mathrm{N}=5, \mathrm{~T}=15, \mathrm{P}=0.031)$. Consequently, even if the proportion of ants correctly responding was somewhat lower than those previously obtained when training the ants before testing them, it could be concluded that the ants could a) once more correctly expect the following, lower, number of elements which would be associated with their food, i.e. the previous less $1, b)$ perceive that the number of elements present near their food was that located far from their food less $1, \mathrm{c})$ correctly perceive the zero (0) element as being less than 1 element, (maybe as being 1 less 1), locating thus the zero at the end of a decreasing series of numbers of elements.

\subsection{Experiment II}

The numerical results of this experiment are given in Table 2, those concerning the training being in the upper part of the table, those concerning the testing being in its lower part. The successive steps of the experiment are illustrated in Figure 4.

Table 2. Results of experiment II made to examine if ants could set the zero at the start of an increasing series of numbers, i.e. before the number 1

\begin{tabular}{|c|c|c|c|c|c|c|c|c|c|c|c|c|c|c|c|c|c|}
\hline \multirow{2}{*}{$\begin{array}{l}\text { Training } \\
\text { Presented } \mathbf{n}^{\text {bers }}\end{array}$} & \multicolumn{17}{|c|}{ Mean numbers of ants around the presented numbers of elements } \\
\hline & \multicolumn{5}{|c|}{4 and $5+$ reward } & \multicolumn{4}{|c|}{3 and $4+$ reward } & \multicolumn{4}{|c|}{2 and $3+$ reward } & \multicolumn{4}{|c|}{1 and $2+$ reward } \\
\hline Colony D & \multicolumn{5}{|c|}{9.4} & \multicolumn{4}{|c|}{9.8} & \multicolumn{4}{|c|}{11.4} & \multicolumn{4}{|c|}{11.8} \\
\hline Colony $\mathbf{E}$ & \multicolumn{5}{|c|}{9.5} & \multicolumn{4}{|c|}{10.3} & \multicolumn{4}{|c|}{8.6} & \multicolumn{4}{|c|}{8.5} \\
\hline Colony $\mathbf{F}$ & \multicolumn{4}{|c|}{10.6} & & \multicolumn{4}{|c|}{10.0} & \multicolumn{4}{|c|}{9.0} & \multicolumn{4}{|c|}{6.4} \\
\hline Testing & \multicolumn{17}{|c|}{ Mean numbers of ants responding to the presented numbers of elements } \\
\hline Presented $\mathbf{n}^{\text {bers }}$ & \multicolumn{3}{|c|}{4 and 5} & \multicolumn{3}{|c|}{3 and 4} & \multicolumn{3}{|c|}{2 and 3} & \multicolumn{3}{|c|}{1 and 2} & \multicolumn{3}{|c|}{1 and 2} & \multicolumn{2}{|c|}{0 and 1} \\
\hline Colony D & 0.7 & and & 3.2 & 0.7 & and & 4.7 & 0.6 & and & 2.9 & 0.5 & and & 2.3 & 0.9 & and & 4.3 & 0.8 and & 4.0 \\
\hline Colony E & 0.7 & and & 2.8 & 0.8 & and & 3.2 & 0.3 & and & 2.7 & 1.1 & and & 4.7 & 0.7 & and & 3.7 & 0.7 and & 3.1 \\
\hline Colony F & 1.0 & and & 4.2 & 0.5 & and & 2.9 & 0.5 & and & 2.5 & 0.7 & and & 3.0 & 0.7 & and & 3.3 & 0.6 and & 3.0 \\
\hline
\end{tabular}

The elements, their numbers, the experimental planning and design are shown in Figures 1 and 2. Means, proportions and statistics are given in the text. The results of the testing sessions made without previously training the ants are written in bold. The first results showed that the ants could expect that the following numbers of elements present near their food and far from it will be 2 and 1 elements respectively (i.e. the previous correct number less 1 element). The second results showed that the ants could expect that the following numbers of elements present near their food and far from it will be 1 element and less than 1 element respectively, and revealed at the same time that the ants perceived 1 element as being higher than 0 element, i.e. locating thus the zero (0) at the start of an increasing series of elements.

During their training to 5 elements located near their food and 4 elements located far from their food, several ants were moving at any time all around these two cues. Meanly, 9.8 ants did so; the ants could thus sufficiently see and memorize the two presented numbers of elements. After two training days, the tested ants mostly moved towards the stand bearing 5 elements. In total, 203 ants, i.e. $81.8 \%$, were counted near the stand with 5 elements, and 45 ants, i.e. $18.2 \%$, were counted near the stand with 4 elements. Summed by four over the experimental time, the numbers of ants of the three colonies present near 5 elements equaled $43,45,36,41,38$, and those of ants present near 4 elements equaled $8,10,10,9,8$. These two series of numbers statistically differed $(\mathrm{N}=5, \mathrm{~T}=$ $15, \mathrm{P}=0.031$ ), the ants having thus correctly preferred 5 elements in the presence of 5 and 4 elements.

During their training to 4 elements situated near their food and 3 elements being far from it, the ants were sufficiently numerous all around these two cues for seeing them and memorizing them. In fact, meanly 10 ants did so. After two training days, the ants, tested in front of 4 and 3 elements, essentially responded to 4 elements. In total, they were 215 , i.e. $85 \%$, to do so while 38 , i.e. $15 \%$, moved near 2 elements. Summed by four over the experimental time, the numbers of ants approaching 4 elements equaled 37,41,41,52, 44, and those of ants approaching 3 elements equaled $3,8,6,9,12$. These two series of numbers statistically differed $(\mathrm{N}=5, \mathrm{~T}=15$, $\mathrm{P}=0.031$ ), the ants having thus learned that 3 elements was the correct response. 

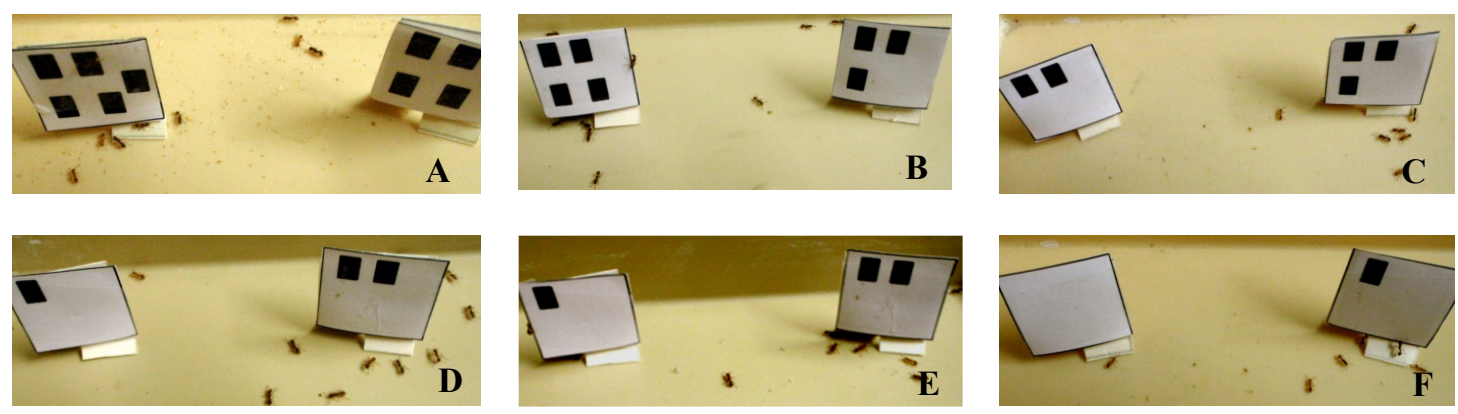

Figure 4. Some views of experiment II

During this experiment, the ants were successively learned to choose $5 v s 4$ elements (A), 4 vs 3 elements (B), 3 vs 2 elements (C), then presented with 2 and 1 elements (D), then learned to choose 2 vs 1 elements (E), and finally presented with 1 and 0 element $(F)$. The photos $\mathbf{D}$ and $\mathbf{F}$ are those of tests made on ants not trained. They revealed that: (D) ants could expect the following number (2) of elements in an increasing series of numbers (1 to 5) present near the food, (F) ants could expect the following number (1) of elements in an increasing series, and perceive 1 element as being higher than 0 element, the latter being thus at the start of an increasing series of numbers.

During their training to 3 elements associated with food and 2 elements not associated with food, meanly 9.7 ants foraged at any time in the vicinity of these two cues. This was enough to allow them seeing and memorizing the two presented numbers of elements. After two training days, the tested ants of the two colonies mostly moved towards the stand bearing 3 elements and far less towards that bearing two elements. The numbers of ants counted near 3 elements equaled 160 , i.e. $86 \%$, and those of ants counted near 2 elements equaled 26, i.e. $14 \%$. Summed by four over the experimental time, the numbers of ants seen near 3 elements equaled 39, 36, 23, 27, 35, and the numbers of ants seen near 2 elements equaled 4, 9, 5, 4, 4. These two series of numbers statistically differed $(\mathrm{N}=5$, $\mathrm{T}=15, \mathrm{P}=0.031$ ), the ants having thus correctly responded to the number of elements (3) present near their food during training. Have the ants perceived that the numbers of elements set near as well as far from their food decreased step by step over the time, and that the number of elements present near the food was always higher than that far from the food, and had in fact one more element? For answering this question, the ants were deprived of food during one day, and were then tested in front of 2 and 1 elements.

When tested in front of 2 and 1 element without having been trained to these numbers, the ants of the three colonies moved more towards 2 elements than towards 1 element. In total, 198 ants, i.e. $81.8 \%$, were seen in front of 2 elements, while 44 ants, i.e. $18.2 \%$, were seen in front of 1 element. Summed by four over the experimental time, the numbers of ants counted near 2 elements equaled 50,43, 35, 40,30, while those of ants counted near 1 element equaled $11,14,5,6,8$. These two series of numbers statistically differed $(\mathrm{N}=5, \mathrm{~T}=15, \mathrm{P}=0.031)$, the ants having thus correctly guessed that the following number of elements present aside their food would be 2 and that the following number of elements located far from their food would be 1 . The present experimental step being an extinction, the ants were then trained, as usually, to 2 elements (present near the food) and 1 element (set far from the food), and were tested two days later in front of these two numbers of elements.

During their two training days to 2 and 1 elements, the ants were rather numerous at any time in the vicinity of these two cues. In fact, meanly 8.9 ants were counted in this vicinity. The ants could thus sufficiently see the two stands for memorizing that the stand with 2 elements was associated with food while the stand with 1 element was far from the food. After training, the tested ants went largely more often to the stand bearing 2 elements than to that bearing 1 element. In total, 226 ants, i.e. $84 \%$, were counted near the former stand while 43 ants, i.e. $16 \%$, were counted near the latter stand. Summed by four over the experimental time, the numbers of ants seen in front of 2 elements equaled 46, 51, 42, 43, 44, and the numbers of ants seen in front of 1 element equaled 12, 9, 5, 8, 9. These two series of numbers statistically differed $(\mathrm{N}=5, \mathrm{~T}=15, \mathrm{P}=0.031)$, the ants having thus correctly chosen the correct number (2) of elements. After this test, the ants were deprived of fresh food during one day, and then tested (without having been trained) in front of 1 and 0 elements.

The ants confronted to 1 and 0 elements (without having been trained), though somewhat hesitating, went however clearly more towards the former number than towards the latter one. The total number of ants counted near 1 element equaled 201, i.e. $83 \%$, and that of ants counted near 0 element equaled 41 , i.e. $17 \%$. Summed by four over the experimental time, the numbers of ants seen near 1 element equaled 48, 52, 33, 34, 34, and those of ants seen near 0 element equaled $8,11,8,8,6$. These two series of numbers statistically differed $(\mathrm{N}=5, \mathrm{~T}=15, \mathrm{P}=0.031)$. 
The ants have thus preferentially reacted to 1 element, the number which would be the following one present near their food, and which would be at the same time larger (with 1 more element) than the number (0) located far from the food.

From this experiment II, it could be concluded that the ants could a) once more correctly expect the following number of elements which would be associated with their food, i.e. the previous one less $1, b)$ perceive that the number of elements present near their food was that located far from their food plus $1, \mathrm{c}$ ) correctly perceive the 1 element as being more than 0 element, (maybe as being 0 plus 1), locating thus the number 1 higher than the 0 , setting consequently the zero at the start of an increasing series of numbers of elements.

\section{Discussion}

Based on previous knowledge about the ability of $M$. sabuleti workers in expecting events and in adding numbers of elements seen simultaneously, we could experimentally show that these ants duly situate the zero at its numerical place, in their numerosity concept, i.e. at the end of a decreasing series of numbers and at the start of an increasing one. Note that, for the latter series, the successive numbers had to be presented in an inverse order because beginning by training the ants to 0 and 1 would only consisted in an operant conditioning to $1 v s 0$ and not in an examination of the ants' ability in setting the zero in its due place.

The concept of zero, and its correct localization inside a series of numbers, is not a frequent ability in the animal kingdom, and is lately acquired by the human children. Several references are given in the introduction section; the following ones are complementary.

To begin with human children, they are firstly initiated to the concept of numbers, to their addition and subtraction using a concrete representation of the numbers, and without the notion of zero (e.g. the zero is absent in the Cuisenaire method used for acquiring the notion of numbers and learning basic arithmetic operations). They are only later confronted to the notion of zero (Michelot, 1966). However, children have an innate notion of 'nothing', of an empty set, long before understanding the symbolic zero (Merritt, \& Brannon, 2013). The processes underlying the human progression from an innate 'sensory' notion of nothing to an ultimate abstract concept of zero is admirably explained by Nieder in his review on the subject (Nieder, 2016). Unfortunately, the teaching of zero can be inadequately performed, as revealed by the investigation of Wheeler and Feghali (1983). Studying several abilities of 4 - 5 years old children (language, visuospatial capabilities, counting, notion of small numbers, notion of zero) revealed that the acquisition of the concept of zero does not essentially depend on the language and visuospatial abilities (Pixner, Dressen, \& Moeller, 2018). Two studies investigating the 3 - 7 years old and 5 $1 / 2-10$ years old children's concept of zero revealed that step by step, the children understood that the zero is a number among the other ones, with a special value, i.e. 'nothing', and with particular rules pertaining to its use (Wellman, \& Miller, 1986).

To come back to the animal kingdom, the concept of zero has been shown, up to now, to be detained by parrots, monkeys and bees (see the introduction section), without however each time specifying if the animal correctly set the zero at its proper arithmetic place. In parrots, the relation between 'none' and 'zero' might be at the limit of their cognitive capabilities (Pepperberg, 1988, 2006). By training monkeys to numerical operations including the zero, Okuyama, Kuki and Mushiake (2015) could show that two types of neurons in the posterior parietal cortex became activated in response to a zero, and this could be a precursor of a non-verbal concept of zero in primates. Let us recall the ability of bees in having a concept of zero, and in localizing correctly this zero in the series of numbers (Howard et al., 2018). Ants, at least the species M. sabuleti, can be added to this short list (M. C. Cammaerts \& R. Cammaerts, 2019a, b, present work).

To conclude about the arithmetic abilities of the ant $M$. sabuleti, let us say that its workers distinguish different numbers of elements, have the concept of 'nothing' based on visual as well as on olfactory perception, and can add two numbers when seeing them simultaneously (but not when seeing them consecutively) (references given in the introduction section). Furthermore, the present work shows that they correctly locate the zero at the end of a decreasing series of numbers and at the start of an increasing series. However, they might react to what they concretely perceived as being a lesser or a higher quantity of elements in comparison with the quantity of elements they earlier perceived. These ants might present their own numerosity abilities without precisely counting, but simply by subitizing the numbers perceived (i.e. using an immediate evaluation of small quantities). They may be unable to cross to abstraction, i.e. to add without seeing at a time what must be added, to have an abstract notion of zero. Note that, according to Biro and Matsuzawa (2001), monkeys may also be in this situation, as are young children when they start comprehending the notion of numbers (Pixner et al., 2018).

No doubt that research will go on about this topic. As for us, since ants could expect the following numbers of elements when trained to a decreasing series of numbers, it may be presumed that they are able to subtract one 
element to a number of these elements, maybe as they did for the addition, i.e. concretely, when seeing the elements side by side and not when seeing them consecutively. Experimenting on this presumption will be the aim of a future work.

\section{Conflict of interests}

The authors declare that there is no conflict of interests regarding the publication of this paper.

\section{References}

Agrillo, C., Dadda, M., Serena, G., \& Bisazza, A. (2008). Do fish count? Spontaneous discrimination of quantity in female mosquitofish. Animal Cognition, 11(3), 495-503. PMID 18247068.

Biro, D., \& Matsuzawa, T. (2001). Use of numerical symbols by the chimpanzee (Pan troglodytes): Cardinals, ordinals, and the introduction of zero. Animal Cognition, 4, 193-199.

Brannon, E. M., \& Herbert, T. S. (1988). Ordering of the Numerosities 1 to 9 by Monkeys. Science, New Series, 282(5389), 746-9.

Cammaerts, M. C. (2008). Visual discrimination of cues differing as for their number of elements, their shape or their orientation, by the ant Myrmica sabuleti. Biologia, 63, 1169-1180.

Cammaerts, M. C., \& Cammaerts, R. (2016a). Ants can expect the time of an event on basis of previous experiences (p. 9). ISRN Entomology. Article ID 9473128.

Cammaerts, M. C., \& Cammaerts, R. (2016b). Spatial expectation of food location in an ant on basis of previous food locations (Hymenoptera, Formicidae). Journal of Ethology, 35(1), 9.

Cammaerts, M. C., \& Cammaerts, R. (2019a). Ants are at the first stage of the notion of zero. International Journal of Biology, 11(1), 54-65.

Cammaerts, M. C., \& Cammaerts, R. (2019b). Ants' notion of zero through the perception of the absence of an odor. International Journal of Biology, 11(2), 1-12.

Cammaerts, M. C., \& Cammaerts, R. (2019c). Ants' capability of adding numbers of identical elements. International Journal of Biology, 11(3), 25-36.

Cammaerts, M. C., \& Cammaerts, R. (2019d). Ants fail to add numbers of same elements seen consecutively. International Journal of Biology, 11(3), 37-48.

Cox, L., \& Montrose, T. (2016). Quantity discrimination in domestic rats, Rattus norvegicus. Animal (Basel), $6(8), 46$.

Hauser, M. D., Carey, S., \& Hauser, L. B. (2000). Spontaneous number representation in semi-free-ranging rhesus monkeys. Proceedings of the Royal Society of London B: Biological Sciences, 267(1445), 829-833.

Howard, S. R., Avarguès-Weber, A., Garcia, J. E., Greentree, A. D., \& Dyer, A. G. (2018). Numerical ordering of zero in honey bees. Science, 360(6393), 1124-1126.

Merritt, D. J., \& Brannon, E. M. (2013). Nothing to it: Precursors to a zero conceept in prescholers. Behavioural Processes, 93, 91-97.

Merritt, D. J., Rugani, R., \& Brannon, E. M. (2009). Empty sets as part of the numerical continuum: Conceptual precursors to the zero concept in rhesus monkeys. Journal of Experimental Psychology: General, 138(2), 258-269.

Michelot, A. (1966). La notion de zéro chez l'enfant. In 'L'enfant', a collection directed by J. Château. Librairie philosophique Vrin J., Paris. Retrieved from http://www.vrin.fr/book.php?code=9782711605705

Nieder, A. (2016). Representing something out of nothing: The drawing of zero. Trends in Cognitive Sciences, 20(11), 830-842. Retrieved from https://www.ncbi.nlm.nih.gov/pubmed/27666660

Okuyama, S., Kuki, T., \& Mushiake, H. (2015). Representation of the Numerosity 'zero' in the Parietal Cortex of the Monkey. Scientific Reports, 5, 1-9(article number: 10059).

Pearce, J. M. (2008). Animal learning and cognition, an introduction. East Sussex, USA, Canada. Psychology Press. Retrieved from http://www.worldcat.org/title/animal-learning-cognition-an-introduction /oclc/682223995

Pepperberg, I. M. (1988). Comprehension of "absence" by an African Grey parrot: Learning with respect to questions of same/different. Journal of the Experimental Analysis of Behavior, 50, 553-564. Retrieved from https://www.ncbi.nlm.nih.gov/pmc/articles/PMC1338917/ 
Pepperberg, I. M. (2006). Grey parrot (Psittacus erithacus) numerical abilities: Addition and further experiments on a zero-like concept. Journal of Comparative Psychology, 120(1), 1-11.

Pepperberg, J. M., \& Gordon, J. D. (2005). Number comprehension by a grey parrot (Psittacus erithacus), including a zero-like concept. Journal of Comparative Psychology, 119(2), 197-209. Retrieved from https://www.ncbi.nlm.nih.gov/pubmed/15982163

Pixner, S., Dresen, V., \& Moeller, K. (2018). Differential Development of Children's Understanding of the Cardinality of Small Numbers and Zero. Frontiers in Psychology, 9, 1-11.

Rodriguez, R. L., Briceno, R. D., Briceno-Aguilar, E., \& Höbel, G. (2015). Nephila clavipes spiders (Araneae: Nephilidae) keep track of captures prey counts: testing for a sense of numerosity in an orb-weaver. Animal Cognition, 18(1), 307-314.

Rose, G. J. (2018). The numerical abilities of anurans and their neural correlates: Insights from neuroethological studies of acoustic communication. Philosophical Transactions of the Royal Society B: Biological Sciences, 373.

Rugani, R., Vallortigara, G., Priftis, K., \& Regolin, L. (2015). Number-space mapping in the newborn chick resembles humans' mental number line. Science, 347(6221), 534-536. ISSN 0036-8075

Siegel, S., \& Castellan, N. J. (1989). Nonparametric statistics for the behavioural sciences. Singapore, McGraw-Hill Book Company. Retrieved from https://www.amazon.com/Sidney -Siegel...Statistics.../B008WDIR6

Wellman, H. M., \& Miller, K. F. (1986). Thinking about nothing: Development of concepts of zero. British Journal of Developmental Psychology, 4(1), 31-42.

Wheeler, M. M., \& Feghali, I. (1983). Much ado about nothing: Preservice elementary school teachers' concept of zero. Journal of Research in Mathematics Education, 14(3), 147-155. Retrieved from https://www.jstor.org/ stable $/ 748378$

Xia, L., Sieman, M., \& Delius, J. D. (2000). Matching of numerical symbols with number of responses by pigeons. Animal Cognition, 3, 35-43.

\section{Copyrights}

Copyright for this article is retained by the author(s), with first publication rights granted to the journal.

This is an open-access article distributed under the terms and conditions of the Creative Commons Attribution license (http://creativecommons.org/licenses/by/4.0/). 